\title{
Adsorption and Degradation Kinetics of Methylene Blue on As-prepared and Calcined Titanate Nanotubes
}

\author{
By Stanislav Kurajica* \\ Iva Minga ${ }^{\dagger}$ \\ Roko Blazic \\ Katarina Muzina ${ }^{+}$ \\ Petra Tominac
}

\begin{abstract}
Titanate nanotubes were prepared by hydrothermal synthesis, followed by Titanate nanotubes were prepared by hydrothermal synthesis, followed by proton exchange, and calcined at $250^{\circ} \mathrm{C}$ for $2 \mathrm{~h}$. The properties of prepared nanotubes were investigated with field emission scanning electron microscopy (FESEM), X-ray diffraction (XRD), adsorption-desorption $\mathrm{N}_{2}$ isotherms and UV-Vis diffuse reflectance spectroscopy (DRS). As-prepared sample displayed strongly aggregated nanotubes with crystal structure of $\mathrm{H}_{2} \mathrm{Ti}_{2} \mathrm{O}_{5} \times \mathrm{H}_{2} \mathrm{O}$. Calcination yielded with loss of interlayer water and partial transformation of nanotubes to anatase phase. Adsorption and photocatalytic decomposition of methylene blue, used as a model pollutant, on as-prepared and calcined titanate nanotubes have been studied. It was established that calcination at $250^{\circ} \mathrm{C}$ for $2 \mathrm{~h}$ improves the adsorption and photocatalytic properties of titanate nanotubes. It was shown that pseudo-second-order model was the most appropriate to describe adsorption of methylene blue on titanate nanotubes. Affinity toward methylene blue of $48.45 \mathrm{mg}^{-1}$ and $95.24 \mathrm{mg}^{-1}$ has been established for as-prepared and calcined titanate nanotubes, while equilibrium adsorption was attained in 120min. Adsorption process is controlled by intraparticle diffusion and surface sorption in both samples, but the contribution of surface sorption is greater for the calcined sample. The pseudo-first-order kinetic is an acceptable model for photocatalytic dye degradation process on titanate nanotubes. It was shown that the calcination slightly increased the photocatalytic activity of titanate nanotubes.
\end{abstract}

Keywords: Adsorption, Calcination, Degradation kinetics, Titanate nanotubes.

\footnotetext{
${ }^{*}$ Professor, University of Zagreb, Croatia.

${ }^{\dagger}$ Research Assistant, University of Zagreb, Croatia.

${ }^{*}$ Research Assistant, University of Zagreb, Croatia

${ }^{+}$Research Assistant, University of Zagreb, Croatia.

- Student, University of Zagreb, Croatia.
} 


\section{Introduction}

Modern science shows an increasing interest in nano-objects and their application due to their unique properties, which are different from those of the corresponding bulk materials (Liu et al., 2015). In general, the size of nanoobjects spans the range between 1 and $100 \mathrm{~nm}$. While the size of nanoparticles is between 1-100 $\mathrm{nm}$ in all three dimensions, nanofibers have only two dimensions on the nanoscale. Hollow nanofibers are called nanotubes. Nanotubes have been intensively studied since the discovery of carbon nanotubes by lijima in 1991 (Iijima, 1991). In recent times, a number of nanotubes made of materials other than carbon, such as boron nitride $\left(\mathrm{BN}_{2}\right)$, iron oxide $\left(\mathrm{Fe}_{2} \mathrm{O}_{3}\right)$, vanadium oxide $\left(\mathrm{V}_{2} \mathrm{O}_{5}\right)$, titanium oxide $\left(\mathrm{TiO}_{2}\right)$ and molybdenum sulfide $\left(\mathrm{MoS}_{2}\right)$, have been prepared and investigated.

Due to particular morphology and unique physical and chemical properties, titanate nanotubes have attracted particular attention of the scientific community (Xiong et al., 2010). They have been extensively studied because of their potential applications in lithium ion batteries, dye-sensitized solar cells, catalysis, photocatalysis and electrocatalysis, gas and humidity sensors, ion exchange and hydrogen storage (Lee et al., 2009). Titanate nanotubes are usually synthesized by three methods: electrochemical method, templated synthesis and hydrothermal synthesis (An'amt et al., 2014). The hydrothermal method invented by Kasuga et al. (1998) is a simple and affordable preparation process, which enabled considerable expansion of titanate nanotubes applicability. The process consists of hydrothermal treatment of $\mathrm{TiO}_{2}$ powder in concentrated $\mathrm{NaOH}$ aqueous solution. The resulting precipitate is then washed with $\mathrm{HCl}$ aqueous solution to produce hydrogen titanate. Titanate nanomaterials with various morphology and diameters can be obtained under different hydrothermal conditions (Lee et al., 2009). The main advantage of the hydrothermal process is the high conversion of titanate nanotubes, which is more than $99 \%$. On the other hand, the disadvantage of this method is the long reaction time, which usually ranged from a day to several days (An'amt et al., 2014).

Titanate nanotubes are characterized by high specific surface areas, favorable chemical interaction with pollutant and high photocatalytic activity. Therefore, they have great potential for usage as adsorbents and photocatalyst (Xiong et al., 2010). Both processes, particularly photocatalysis, can be considered as a green chemistry methods (Buchholcz et al., 2017). The process of photodegradation starts when $\mathrm{TiO}_{2}$ absorbs a UV radiation of energy equal or higher than its band gap. This leads to the formation of free electrons in the conduction band and holes in the semiconductor valence band. The energized electrons have two options-they can either recombine with the holes dissipating the absorbed energy as heat, or the electron-hole pairs can participate in redox reactions. They can react with electron acceptors/donors adsorbed on the surface of the photocatalyst. Essentially, it is accepted that the initial steps of photocatalytic degradation of a species is the reaction with extremely reactive but short-lived hydroxyl radicals $\left(\mathrm{OH}^{\bullet}\right)$ or direct hole trapping. The hydroxyl radicals are formed either on the highly hydroxylated semiconductor surface or 
by direct oxidation of the pollutant molecules under UV radiation. After successive free radical attack and fragmentation, most organics are mineralized to water, carbon dioxide and mineral acids (Salehi et al., 2012).

The investigation of adsorption and degradation kinetics of various pollutants on titanate nanotubes could improve the application of this material in environment protection. For the investigation of adsorption and photodegradation processes methylene blue is often used since it may be easily monitored by the decolorization of its solution. Methylene blue is a familiar basic dye extensively used for dying cotton, silk and wool. It is not considered acutely toxic, but it can have various harmful effects such as nausea, vomiting, diarrhea and gastritis (Salehi et al., 2012). In general, synthetic dyestuffs can cause substantial environmental pollution and pose a serious health risk, as a result of their largescale production, extensive application in various industries and toxic and cancerogenic properties. Lately, heterogeneous photocatalysis using semiconductors such as titanium dioxide has attracted a lot of attention because it can mineralize organic dyes completely into water, carbon dioxide and other nontoxic inorganic compounds without bringing secondary pollution (Chekir et al., 2016). Since methylene blue is a cationic dye, its adsorption is preferable on the negatively charged surface of titanate nanotubes (Bavykin et al., 2010). Photocatalytic degradation rate depends on photocatalyst-pollutant molecule interaction and good adsorption of pollutant molecule can improve the efficiency of photocatalytic degradation (Xiong et al., 2010).

The morphology, electronic structure and crystallinity of titanate nanotubes arrays are known to impact their adsorption and photocatalytic characteristics and can be controlled by the processing conditions (Hosseinpour et al., 2014). Adsorption and photocatalytic degradation of methylene blue on titanate nanotubes were subject of several investigation, most recent ones being those of Subramaniam et al. (2017) and Sandoval et al. (2017). It has been reported that calcination of titanate nanotubes benefited the photocatalytic activity of this material (Xiong et al., 2010).

In this work, titanate nanotubes prepared by a hydrothermal reaction were calcined at $250^{\circ} \mathrm{C}$ for $2 \mathrm{~h}$. The influence of calcination on crystal structure, specific surface area and bandgap has been investigated. Methylene blue, common basic dye, was used as a model pollutant. Adsorption and photocatalytic decomposition of methylene blue on as-prepared and calcined titanate nanotubes have been studied.

\section{Methodology}

Nanotubes were synthesized by the hydrothermal treatment as described by Umek et al. (2007). Briefly, 7g of the titania powder Evonik P25 (Evonik, Germany) were added in a $56 \mathrm{~cm}^{3}$ of $10 \mathrm{M} \mathrm{NaOH}$ (Kemika, Croatia) aqueous solution and mixed on a magnetic stirrer for $90 \mathrm{~min}$ and sonicated for $15 \mathrm{~min}$. The mixture was then transferred into an autoclave with a PTFE container inside. The degree of filling was $\sim 80 \%$. The autoclave was kept in the oven at 
the temperature of $135^{\circ} \mathrm{C}$ for $72 \mathrm{~h}$. The precipitates were recovered by centrifugation and rinsed with distilled water to remove excess $\mathrm{NaOH}$, then with $0.1 \mathrm{M} \mathrm{HCl}$ (Sigma - Aldrich, USA) solution to enable sodium ion exchange with hydrogen and produce hydrogen titanate, and finally with distilled water and ethanol to remove excess $\mathrm{HCl}$. The resultant nanotubes were then dried at $60^{\circ} \mathrm{C}$ for $24 \mathrm{~h}$.

The morphology of titanate nanotubes was investigated with a field emission scanning electron microscope (FESEM) Supra 35LV (Carl Zeiss, Germany) operating at $1 \mathrm{kV}$. Sample for FESEM characterization was prepared by fixing nanotubes on a sample holder using double-sided carbon conductive tape. The sample particles were then gold-coated by vapor deposition using a vacuum sputter.

The powder X-ray diffraction (XRD) was accomplished by using diffractometer XRD 6000 (Shimadzu, Japan) with $\mathrm{CuK} \alpha$ radiation. Data were collected between 5 and $65^{\circ} 2 \theta$, in a step scan mode with steps of $0.02{ }^{\circ} 2 \theta$ and counting time of $0.6 \mathrm{~s}$.

Surface area was determined by Brunauer-Emmet-Teller (BET) $\mathrm{N}_{2}$ gas adsorption-desorption isotherms obtained at $77 \mathrm{~K}$ on an ASAP-2000 equipment (Micromeritics, USA). Samples were previously degassed at $100^{\circ} \mathrm{C}$ under a dynamic vacuum of $1.3 \times 10^{-2} \mathrm{~Pa}$. Pore size distributions were calculated from the desorption isotherms by the Barret-Joyner-Halenda (BJH) model.

The UV-Vis spectrum of the prepared sample was obtained using DRS Lambda 35 (Perkin-Elmer, USA) equipped with an integrating sphere. The spectra were recorded at room temperature in the wavelength range of $200-800 \mathrm{~nm} . \mathrm{BaSO}_{4}$ was used as a reference. The diffuse reflectance spectra were transformed by performing a Kubelka-Munk transformation of the measured reflectance according to:

$F(\mathrm{R})=\left(1-\mathrm{R}^{2}\right) /(2 \mathrm{R})$,

where $F(\mathrm{R})$ is proportional to the extinction coefficient $(\alpha)$ and $R$ is the reflectance of the "infinitely thick" layer of the solid (Valencia et al., 2010). The bandgap energy, $E_{\mathrm{g}}$, was estimated by plotting modified Kubelka-Munk function, $(F(\mathrm{R}) h v)^{n}$, vs. photon energy $(h v)$, the so-called Tauc's plot, followed by extrapolation of the linear region of high slope region onto the energy axis. In modified Kubelka-Munk function $h$ is the Planck's constant (4.13566733 $\mathrm{eVs})$ and $v$ is frequency, quotient of light velocity $\left(c=299792458 \mathrm{~m} \mathrm{~s}^{-1}\right)$ and wavelength $(\lambda / \mathrm{m})$. The exponent $n$ is associated with electronic transition in the course of optical absorption process and is theoretically equal to $1 / 2$ and 2 for indirect and direct allowed transitions, respectively (Valencia et al., 2010).

For the adsorption kinetics investigation, $0.1000 \mathrm{~g}$ of titanate nanotubes was added to $500 \mathrm{~mL}$ of $20 \mathrm{mg} \mathrm{L}^{-1}$ methylene blue (VWR Chemicals, USA) solution in a borosilicate cylindrical glass vessel with $100 \mathrm{~mm}$ diameter and $120 \mathrm{~mm}$ height. After being placed in the vessel, the mixture was stirred in dark at room temperature using a magnetic stirrer operating at 200rpm to maintain a homogeneous suspension. 
As UV source for the photodegradation kinetics investigation a Pen Ray lamp (UVP Products, USA), cat. no. 90-0012-01, with radiation wavelength $254 \mathrm{~nm}$ and emission intensity of $2 \mathrm{~mW} \mathrm{~cm}^{-2}$, was used. The lamp was placed inside a quartz glass tube and the tube was placed axially in the center of the borosilicate vessel. The lamp was switched on after 120min of adsorption and photodegradation experiment was carried out at room temperature.

In order to determine methylene blue concentration, aliquots of $4 \mathrm{ml}$ were withdrawn from the suspension at appropriate time intervals, while a filter was used to separate solid particles. The concentrations were determined using UVVis spectrophotometer Cary 1E (Varian, USA). Absorption at wavelength of $664 \mathrm{~nm}$ (where it was maximal) has been computed to methylene blue concentration using standard calibration curve. The adsorption capacity at time $t$ has been calculated through equation:

$Q_{\mathrm{t}}=\left(C_{0}-C_{\mathrm{t}}\right) V / m$

where $C_{0}$ is the initial concentration of methylene blue in $\mathrm{mg} \mathrm{g}^{-1}, C_{\mathrm{t}}$ is the concentration of methylene blue after time $t$ in $\mathrm{mg} \mathrm{g}^{-1}, V$ is the initial volume of methylene blue solution in $\mathrm{L}$ and $m$ is the mass of added titanate nanotubes in g. The photo-degradation was monitored using the same equation, but in this case $C_{0}$ was the concentration of methylene blue after $120 \mathrm{~min}$ of adsorption in $\mathrm{mg} \mathrm{g}^{-1}$.

Figure 1. FESEM Micrographs of As-prepared Titanate Nanotubes

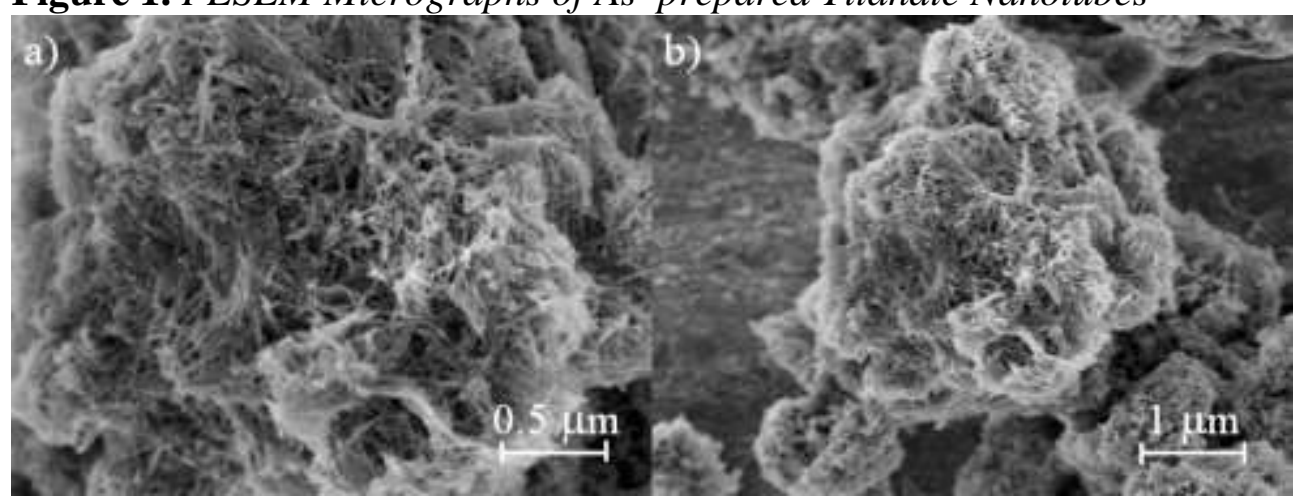

\section{Results and Discussion}

FESEM image of the as-prepared sample (Figure 1a) revealed that titania particles were fully transformed into nanotubes. In order to reduce the surface energy, nanotubes are agglomerated into randomly tangled fibrous network (Figure 1b).

XRD pattern of the as-prepared sample (hydrothermal synthesis and acid treatment), is shown in Figure 2. Diffraction peaks were observed at approximately $9.1,24.4,28.0$ and $48.4^{\circ} 2 \theta$. Broad and weak diffraction peaks reveal nanoscale character of the obtained material. Obtained XRD pattern is 
consistent with hydrogen titanium oxide hydrate, $\mathrm{H}_{2} \mathrm{Ti}_{2} \mathrm{O}_{5} \times \mathrm{H}_{2} \mathrm{O}$ (ICDD file: 47-0124). The different intensities or even absence of some peaks as compared to the ICDD file can be justified by the limited number of titanate layers in tubular shape (Maxim et al., 2011). Intense peak around $9.1^{\circ} 2 \theta$ is attributed to the interlayer distance. According to Bragg equation this distance is approximately $0.97 \mathrm{~nm}$. Upon heat treatment at $250^{\circ} \mathrm{C}$ a significant decrease in intensity of nanotubes peaks as well as a shift of $9.1^{\circ} 2 \theta$ peak to $10.8^{\circ} 2 \theta$ (which is equivalent to $0.82 \mathrm{~nm}$ interlayer distance) can be observed. This shift towards higher $2 \theta$ value, i.e. the reduction of interlayer distance, can be interpreted as loss of interlayer water (Suzuki and Yoshikawa, 2004). On the other hand, the decrease of nanotubes peaks intensity is a consequence of partial transformation of nanotubes to anatase phase, which is obvious from the appearance of anatase (ICDD file: 21 1272) diffraction peaks. Therefore, the sample calcined at $250^{\circ} \mathrm{C}$ for $2 \mathrm{~h}$ is composed of a mixed phase of titanate nanotubes and anatase. Similar thermal stability of titanate nanotubes has been observed by Zhang et al. (2007). Thermal treatment at $500^{\circ} \mathrm{C}$ brings about complete transformation of titanate nanotubes to anatase, while after thermal treatment at $750^{\circ} \mathrm{C}$ the whole sample is composed of rutile (ICDD file: 21-1276), which is not shown here.

Figure 2. XRD Patterns of As-prepared Nanotubes and Nanotubes Thermally Treated at $250^{\circ} \mathrm{C}$ for $2 \mathrm{~h}$

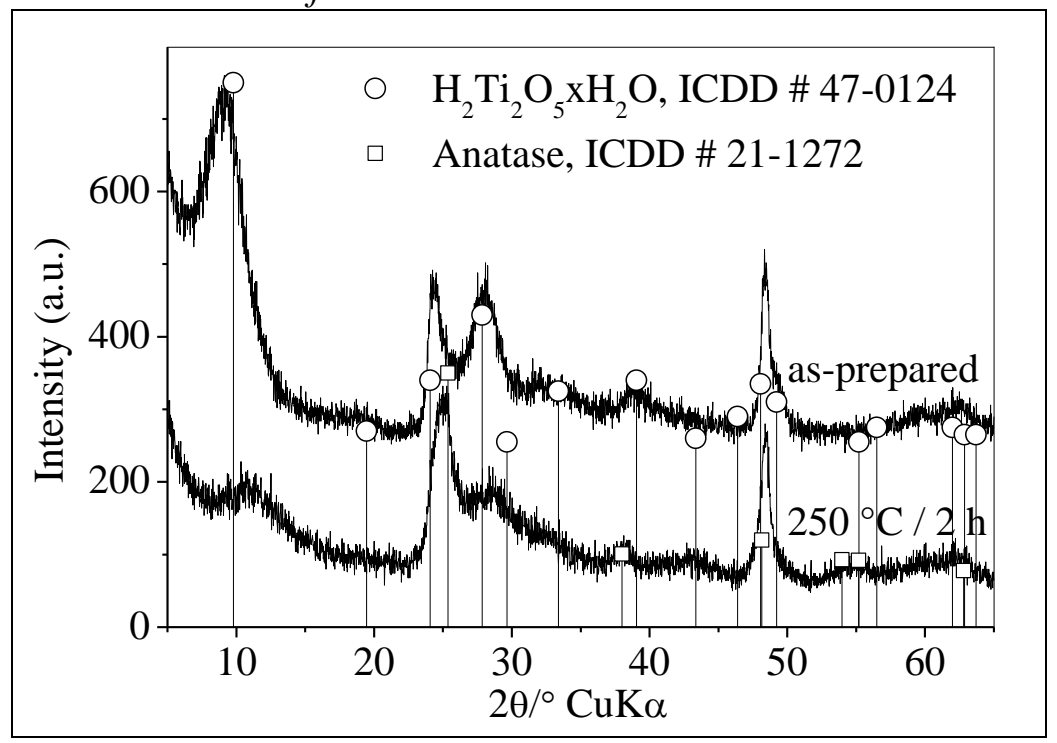

The adsorption-desorption isotherms of nitrogen on as-prepared nanotubes and nanotubes thermally treated at $250^{\circ} \mathrm{C}$ for $2 \mathrm{~h}$ (Figure 3 ) are of type IV exhibiting $\mathrm{H} 3$ hysteresis loops according to the IUPAC classification. Such isotherms are usually associated with capillary condensation in mesoporous structures (Abida et al., 2013). According to Bavykin and Walsh (2009), only the external and internal geometrical surfaces of titanate nanotubes are accessible to nitrogen molecules, which enable classification of nanotubes as mesoporous materials. The BET specific surface area of the as-prepared titanate nanotubes was determined to be $334.87 \mathrm{~m}^{2} \mathrm{~g}^{-1}$. Specific surface area depends greatly on 
synthesis conditions and post-treatment but similar values for specific surface areas of titanate nanotubes are reported (Jose et al., 2016; Buchholcz et al., 2017; Sandoval et al., 2017; Subramaniam et al., 2017), while nanotubes thermally treated at $250^{\circ} \mathrm{C}$ for $2 \mathrm{~h}$ showed specific surface area of $301.80 \mathrm{~m}^{2} \mathrm{~g}^{-1}$. The drop in surface area after calcination is a consequence of partial transformation to anatase (Morgado et al., 2006). On the other hand, no significant difference in pore size distribution could be observed (Figure 3, inset). The majority of the pores is large and can be attributed to the voids in the aggregation of the nanotubes. Only pores smaller than 10nm may correspond to the pores inside the nanotubes (Lee et al., 2009). Calcination of nanotubes at higher temperatures results in considerable decrease of specific surface area. The BET specific surface area of titanate nanotubes calcined at 500 and $750^{\circ} \mathrm{C}$ yields 106.06 and $38.76 \mathrm{~m}^{2} \mathrm{~g}^{-1}$, respectively.

Figure 3. $N_{2}$ Adsorption-Desorption Isotherms and Pore Size Distribution (Inset) of the As-prepared Nanotubes and Nanotubes Thermally Treated at $250^{\circ} \mathrm{C}$ for $2 \mathrm{~h}$

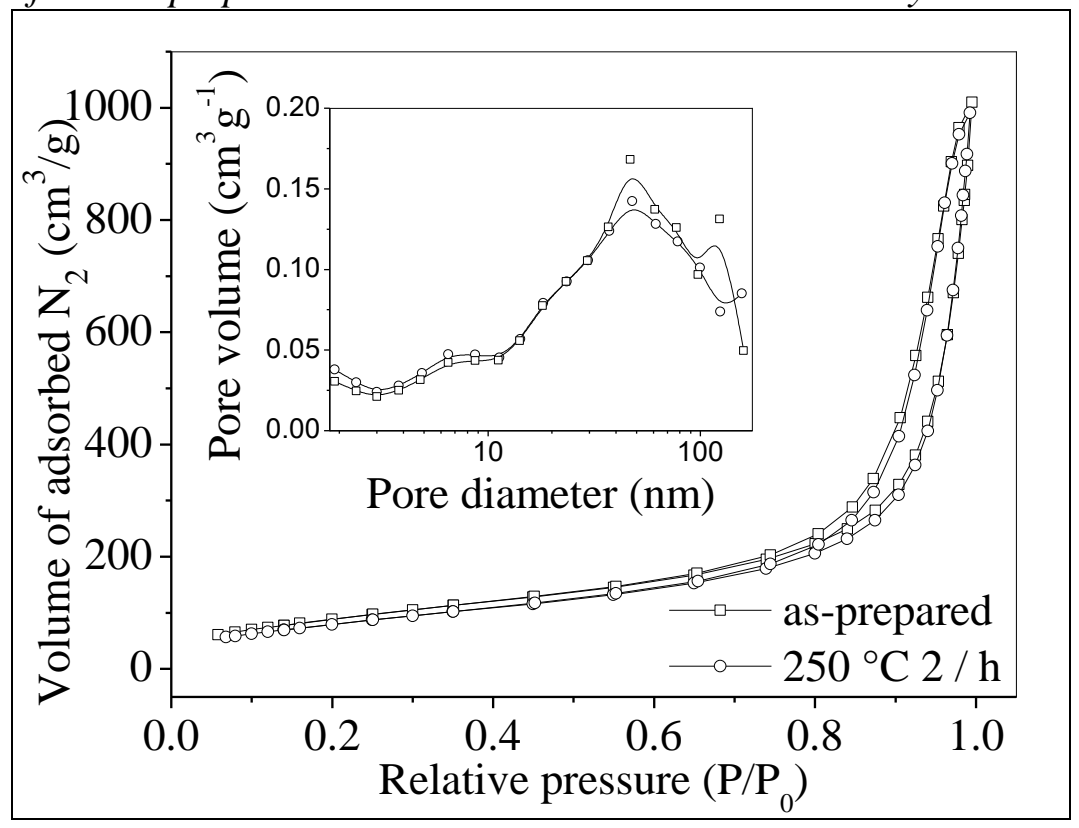

In order to determine optical band gap of the as-prepared nanotubes and nanotubes thermally treated at $250^{\circ} \mathrm{C}$ for $2 \mathrm{~h}$, UV-Visible diffuse reflectance spectra were recorded (Figure 4, inset). Both samples showed absorption in the UV region. However, red shift of the absorption edge (to longer wavelengths i.e. lower energy) can be observed for the sample thermally treated at $250^{\circ} \mathrm{C}$ for $2 \mathrm{~h}$. The indirect optical band gap energy of the titanate nanotubes was calculated by plotting the function $(F(R) h v)^{0.5}$ vs. $E$ (Tauc plot) and extrapolating the linear part of the curve to $F(\mathrm{R})=0$ (Figure 4 ). The $E_{\mathrm{g}}$ value obtained for the as-prepared sample was $3.45 \mathrm{eV}$, which is in agreement with previous titanate nanotubes investigations (Morgado et al., 2007), although lower values were also reported (Jose et al., 2016; Buchholcz et al., 2017; Sandoval et al., 2017) while the thermally treated sample showed $E_{\mathrm{g}}$ value of $3.2 \mathrm{eV}$. As it was shown earlier, heat treatment lead to intralayer dehydration of nanotubes which, 
according to literature (Zhang et al., 2004), cause the formation of oxygen and hydrogen vacancies thus inducing defect states and reducing the bandgap of titanate nanotubes (Sun et al., 2015). Also, partial transformation to anatase, having narrower bandgap, occurs. Anatase is an indirect band gap semiconductor having $\mathrm{E}_{\mathrm{g}}$ value around $3.2 \mathrm{eV}$ (Luttrell et al., 2014), so the calculated value is the same as for anatase. Thermal treatment at $500^{\circ} \mathrm{C}$ does not change the $\mathrm{E}_{\mathrm{g}}$ value, while the sample thermally treated at $750^{\circ} \mathrm{C}$ yields with $\mathrm{E}_{\mathrm{g}}$ value of 3.1, which is close to the literature value for rutile, which is $3.0 \mathrm{eV}$ (Luttrell et al., 2014). Since rutile is a direct band gap semiconductor, $E_{\mathrm{g}}$ value was calculated by plotting the function $(F(R) h v)^{2}$ vs. $E$.

Figure 4. Tauc's Plot for Indirect Transition and UV-Vis Reflectance Spectra (Inset) of the As-prepared Nanotubes and Nanotubes Thermally Treated at $250^{\circ} \mathrm{C}$ for $2 h$

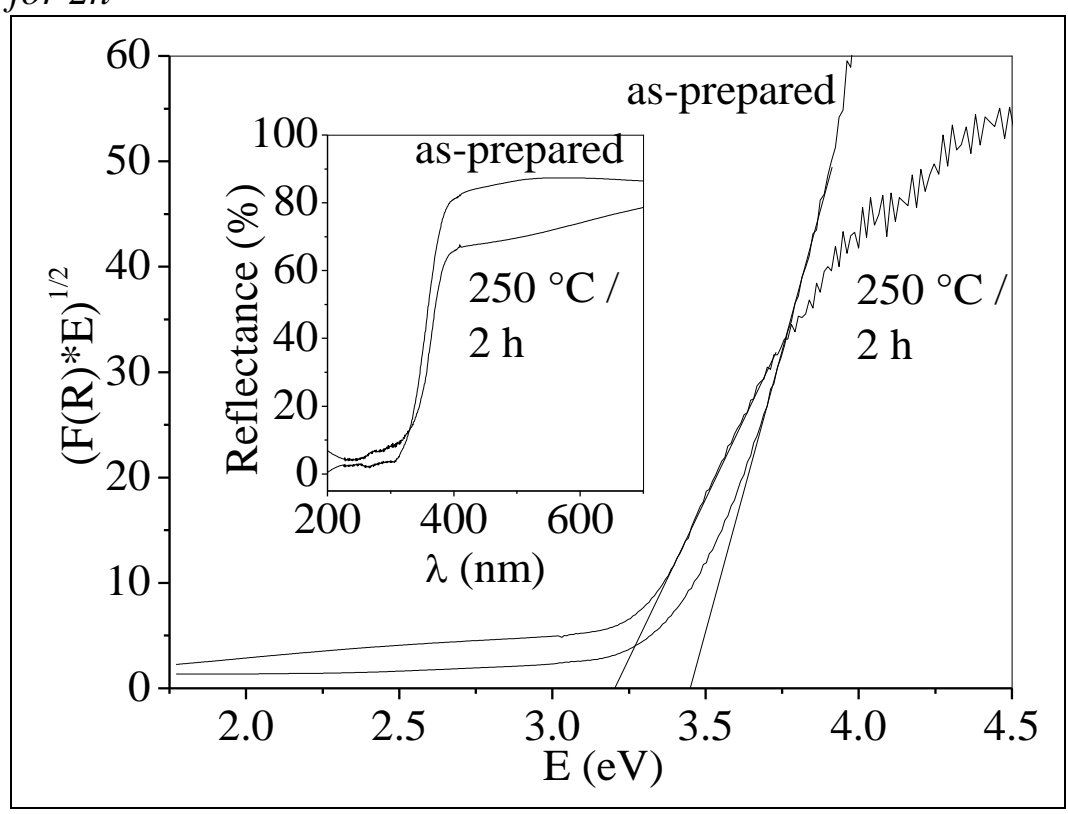

To investigate adsorption kinetics and to determine the time necessary to establish equilibrium adsorption, batch adsorption experiments have been conducted. The effect of contact time on adsorption of methylene blue onto titanate nanotubes is shown in Figure 5. As can be observed, after the initial rapid adsorption, equilibrium is reached in approximately $120 \mathrm{~min}$ for both samples. The adsorption equilibrium capacities are 47 and $93 \mathrm{mg} \mathrm{g}^{-1}$ for as-prepared and calcined sample, respectively. Comparison with literature results is not straight forward since various nanotubes types were used and adsorption conditions utilized, for example Jose et al. (2016) reported MB adsorption capacity of hydrogen phosphate modified titanate nanotubes of $139 \mathrm{mg} \mathrm{g}^{-1}$ for initial concentration of $\mathrm{MB}$ of $0.25 \mathrm{mmol} \mathrm{L}^{-1}$. Obtained total adsorption capacities are quite high and are the consequence of good affinity between dye molecules in cationic form and titanate nanotubes with anionic character surface (Bavykin et al., 2010). Namely, in aqueous suspensions titanate nanotubes develop negative zeta potential due to dissociation (Bavykin et al., 2010): 


\section{$\mathrm{H}_{2} \mathrm{Ti}_{3} \mathrm{O}_{7} \leftarrow \rightarrow \mathrm{H}^{+}+\mathrm{HTi}_{3} \mathrm{O}_{7}^{-}$}

On the other hand, methylene blue in aqueous solution dissociates into methylene blue cation and chloride anion. As a matter of fact, characteristic deep blue color is due to methylene blue cation, while methylene blue is a dark green powder (El-Wakil et al., 2013).

Of course, high specific surface area is beneficial, too, but not decisive since titanate nanotubes with greater specific surface area (as-prepared) show lesser equilibrium capacity. It is possible that the calcined sample possesses a greater number of active sites for the dye molecules adsorption.

Figure 5. Effect of Contact Time on the Adsorption of Methylene Blue onto Asprepared Nanotubes and Nanotubes Thermally Treated at $250^{\circ} \mathrm{C}$ for $2 \mathrm{~h}$. The Lines are introduced as Guidelines for the Eye.

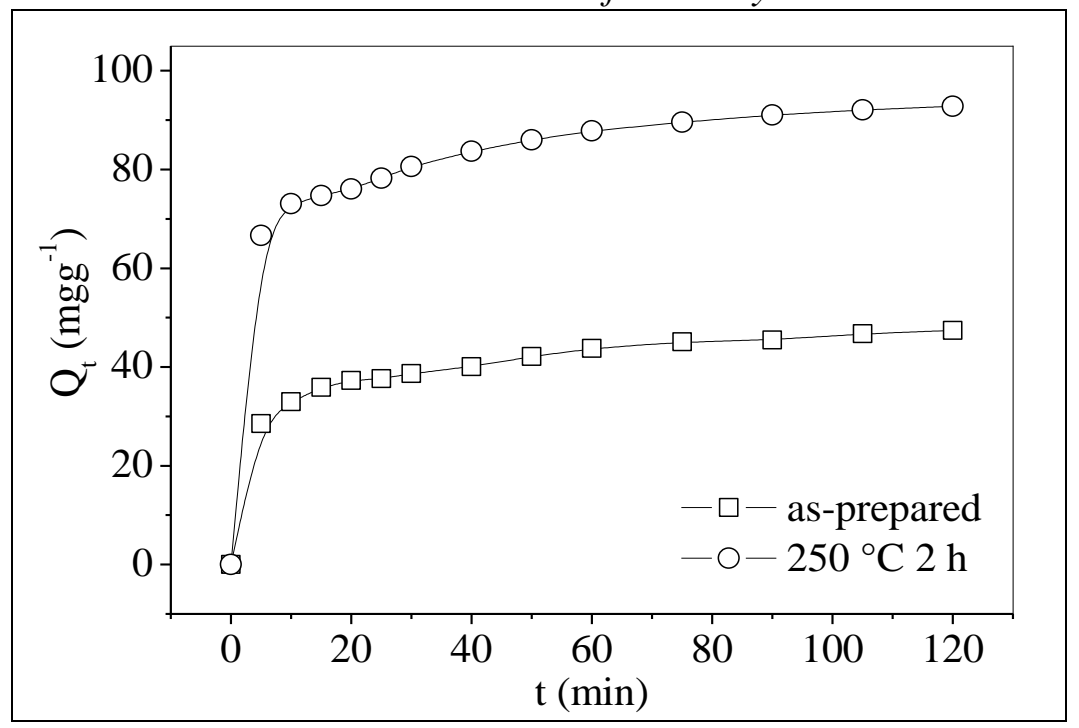

The adsorption kinetics data was fitted to pseudo-second-order model since previous investigations (Xiong et al., 2010; Hu et al., 2011; Jose et al., 2016) showed that this model describes well the adsorption kinetics of methylene blue onto titanate nanotubes. The pseudo-second-order model can be expressed by the following linear form (Xiong et al., 2010):

$t / Q_{\mathrm{t}}=1 /\left(k_{\mathrm{so}} Q_{\mathrm{e}}^{2}\right)+t / Q_{\mathrm{e}}$,

where $Q_{\mathrm{t}}\left(\mathrm{mg} \mathrm{g}^{-1}\right)$ is the amount of methylene blue adsorbed at time $\mathrm{t}, k_{\mathrm{so}}(\mathrm{g}$ $\left.\mathrm{mg}^{-1} \mathrm{~min}^{-1}\right)$ is the pseudo-second-order rate constant and $Q_{\mathrm{e}}\left(\mathrm{mg} \mathrm{g}^{-1}\right)$ is the amount of methylene blue adsorbed at equilibrium.

The plots of $t / Q_{t}$ versus $t$ for the as-prepared nanotubes and nanotubes thermally treated at $250^{\circ} \mathrm{C}$ for $2 \mathrm{~h}$ are given in Figure 6 . The kinetic parameters $Q_{\mathrm{e}}$ and $k_{2}$ were calculated from the slope and intercept and listed in Table 1 together with the corresponding linear regression correlation coefficient, $\mathrm{R}^{2}$. From Figure 6 a linear dependence could be observed and correlation coefficients 
higher than 0.99 have been obtained (Table 1). Such high correlation coefficients indicate that experimental data exhibit a good compliance with pseudo-secondorder kinetic equation, i.e. that the adsorption kinetics of methylene blue onto titanate nanotubes followed the pseudo-second-order kinetic model. The compliance with the pseudo-second-order model suggested that chemical sorption involving valence forces through sharing or exchange of electrons between adsorbent and adsorbate might be significant (Xiong et al., 2010). Different rate constants for the two samples imply greater difference in affinity of methylene blue toward the as-prepared and calcined sample.

Figure 6. Linear Plots of Pseudo-Second-Order Kinetic Model of Adsorption of Methylene Blue of the As-prepared Nanotubes and Nanotubes Thermally Treated at $250^{\circ} \mathrm{C}$ for $2 \mathrm{~h}$

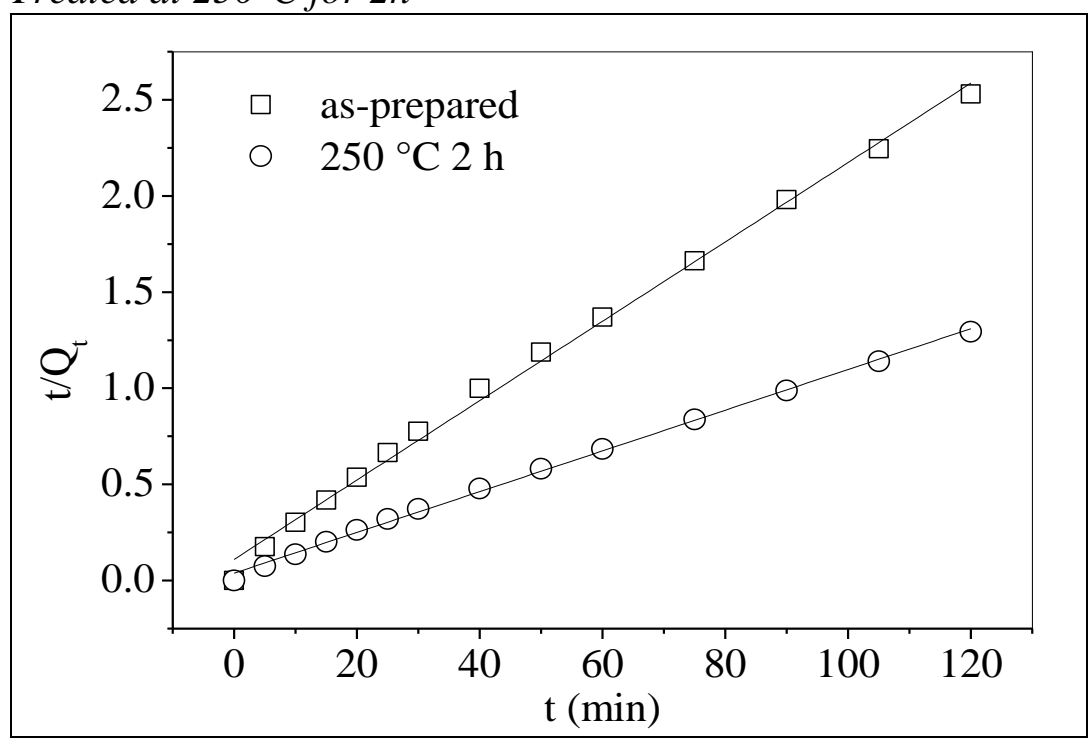

Table 1. The Constants of Pseudo-Second-Order Kinetic Model and Correlation Coefficients for the Adsorption of Methylene Blue onto As-prepared Nanotubes and Nanotubes Thermally Treated at $250^{\circ} \mathrm{C}$ for $2 \mathrm{~h}$

\begin{tabular}{|l|l|l|l|}
\hline & $\mathbf{R}^{\mathbf{2}}$ & $\boldsymbol{Q}_{\mathbf{e}}\left(\mathbf{m g ~ g}^{-1}\right)$ & $\boldsymbol{k}_{\mathbf{s o}}\left(\mathbf{g ~ m g}^{-1} \mathbf{m i n}^{-1}\right)$ \\
\hline As-prepared & 0.99628 & 48.45 & $3.88 \times 10^{-3}$ \\
\hline Calcined & 0.99832 & 95.24 & $2.87 \times 10^{-3}$ \\
\hline
\end{tabular}

In order to gain insight into the mechanism and rate controlling step of the adsorption process, the adsorption kinetics data were analyzed by the Weber's intraparticle diffusion model. This model can be expressed as (Xiong et al., 2010):

$Q_{\mathrm{t}}=k_{\mathrm{id}} t^{0.5}+C$,

where $\mathrm{k}_{\mathrm{id}}\left(\mathrm{mg} \mathrm{g}^{-1} \mathrm{~min}^{-1 / 2}\right)$ is the intraparticle diffusion rate constant and $C$ is a constant indicating the boundary layer effect (surface sorption) contribution. According to Weber's model, if intraparticle diffusion is involved in the 
adsorption process, the plot of the amount of dye adsorbed at time $\mathrm{t}\left(Q_{\mathrm{t}}\right)$ versus the square root of time should be linear. If this line passes through the origin $(C$ $=0$ ), then intraparticle diffusion is the sole rate controlling step and if the line do not pass through the origin $(C \neq 0)$, this is indicative of some degree of boundary layer control (Gandhimathi et al., 2013). Plots of $Q_{\mathrm{t}}$ versus $t^{1 / 2}$ are given in Figure 7 and the values of $k_{\mathrm{id}}, C$ and corresponding linear regression correlation coefficient are given in Table 2.

Figure 7. Linear Plot of Weber Intraparticle Diffusion Model for the Adsorption of Methylene Blue of the As-prepared Nanotubes and Nanotubes Thermally Treated at $250^{\circ} \mathrm{C}$ for $2 \mathrm{~h}$

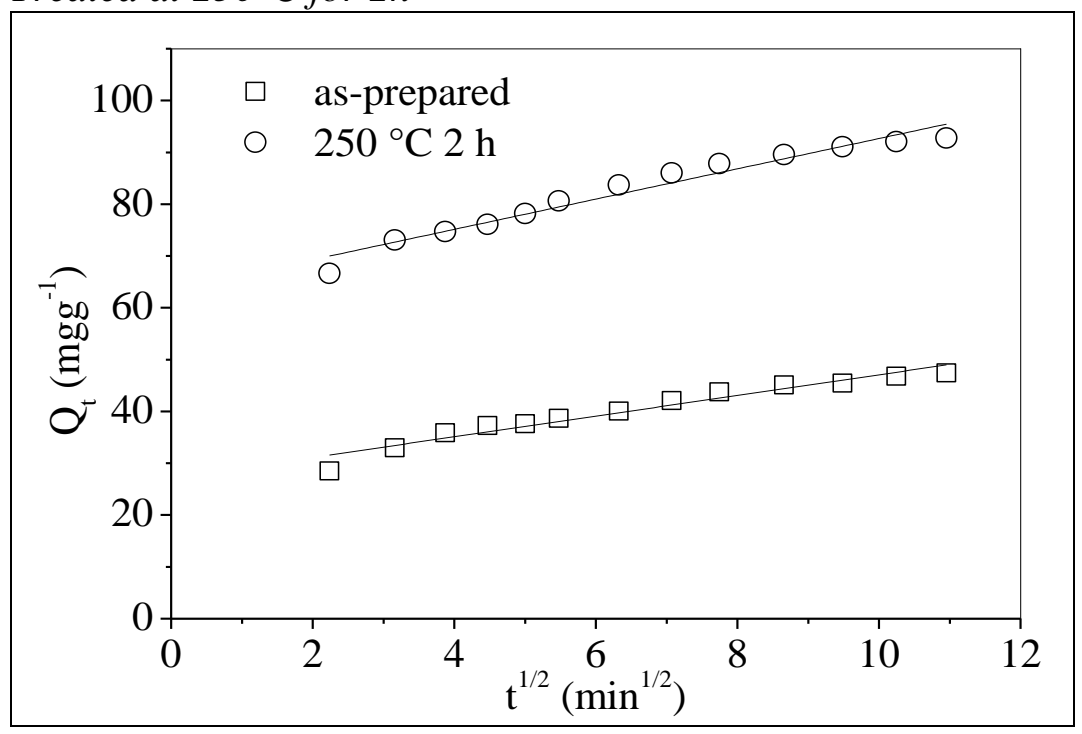

Table 2. The Constants of Weber Intraparticle Diffusion Model and Correlation Coefficients for the Adsorption of Methylene Blue onto As-prepared Nanotubes and Nanotubes Thermally Treated at $250^{\circ} \mathrm{C}$ for $2 \mathrm{~h}$

\begin{tabular}{|l|l|l|l|}
\hline & $\mathbf{R}^{2}$ & $\boldsymbol{C}$ & $\boldsymbol{k}_{\text {id }}\left(\mathbf{m g ~ g}^{-1} \mathbf{m i n}^{-1 / 2}\right)$ \\
\hline As-prepared & 0.94667 & 27.13 & 1.99 \\
\hline Calcined & 0.99832 & 63.44 & 2.87 \\
\hline
\end{tabular}

As can be observed in Figure 7, the plots of $Q_{\mathrm{t}}$ versus $t^{0.5}$ are linear for both samples, but deviate from the origin suggesting that both processes, intraparticle diffusion and surface sorption, control adsorption rate of methylene blue onto titanate nanotubes. The $C$ value indicates the contribution of intraparticle diffusion in apsorption rate control; the smaller the $C$ is, the greater is the contribution of intraparticle diffusion. According to this rule, the interparticle diffusion contribution is greater for the as-prepared sample. At the same time, surface sorption is emphasized for the calcined sample pointing out to a greater number of active sites for the dye molecules adsorption.

In order to evaluate the photocatalytic performance of the as-prepared and calcined titanate nanotubes, the dependence of methylene blue concentration on irradiation time in presence of titanate nanotubes has been measured and 
Vol. 5, No. $1 \quad$ Kurajica et al.: Adsorption and Degradation Kinetics of Methylene...

presented in Figure 8. Both investigated samples showed notable degradation confirming that titanate nanotubes are active photocatalyst for methylene blue. To estimate the degradation kinetic rate pseudo-first-order kinetic model was used:

$-\ln \left(C_{\mathrm{t}} / C_{0}\right)=k t$,

where $C_{\mathrm{t}}$ is the concentration of methylene blue after photodegradation time $t$, $C_{0}$ is the initial methylene blue concentration after $120 \mathrm{~min}$ stirring in the dark and $\mathrm{k}$ is the kinetic constant (Sun et al., 2015).

Figure 8. Effect of Irradiation Time on the Degradation of Methylene Blue on As-prepared Nanotubes and Nanotubes thermally treated at $250^{\circ} \mathrm{C}$ for $2 \mathrm{~h}$. The Lines are introduced as Guidelines for the Eye

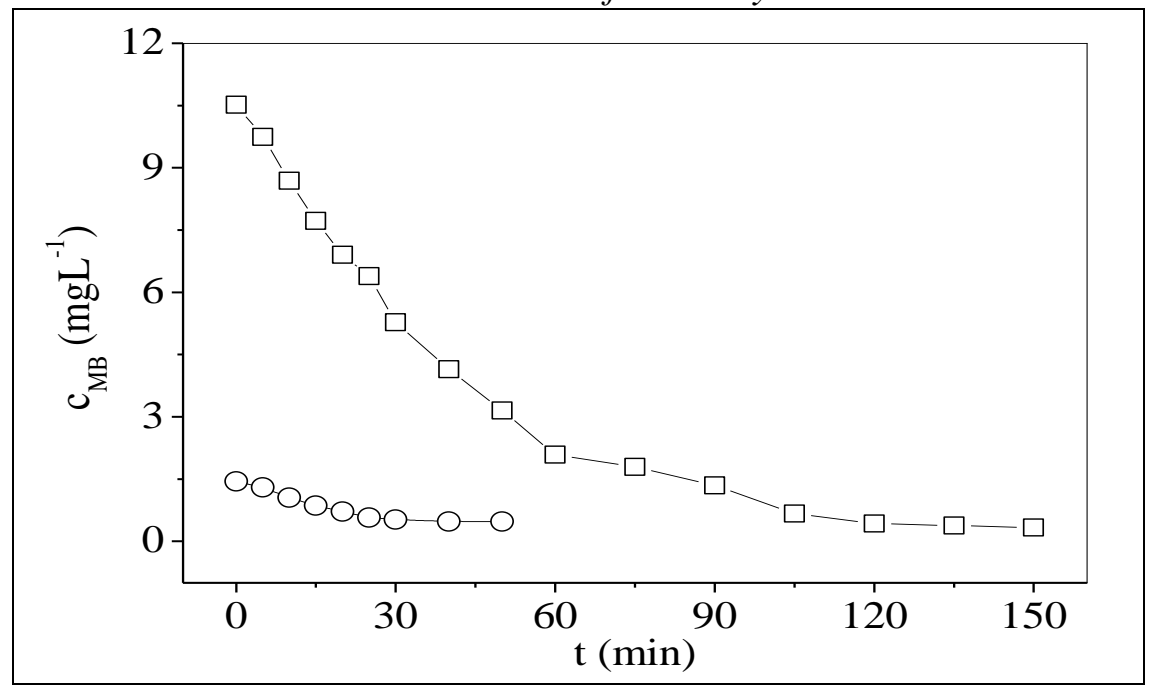

Figure 9. Linear Plots of Pseudo-First-Order Kinetic Model of Methylene Blue Degradation on As-prepared Nanotubes and Nanotubes thermally treated at $250^{\circ} \mathrm{C}$ for $2 \mathrm{~h}$

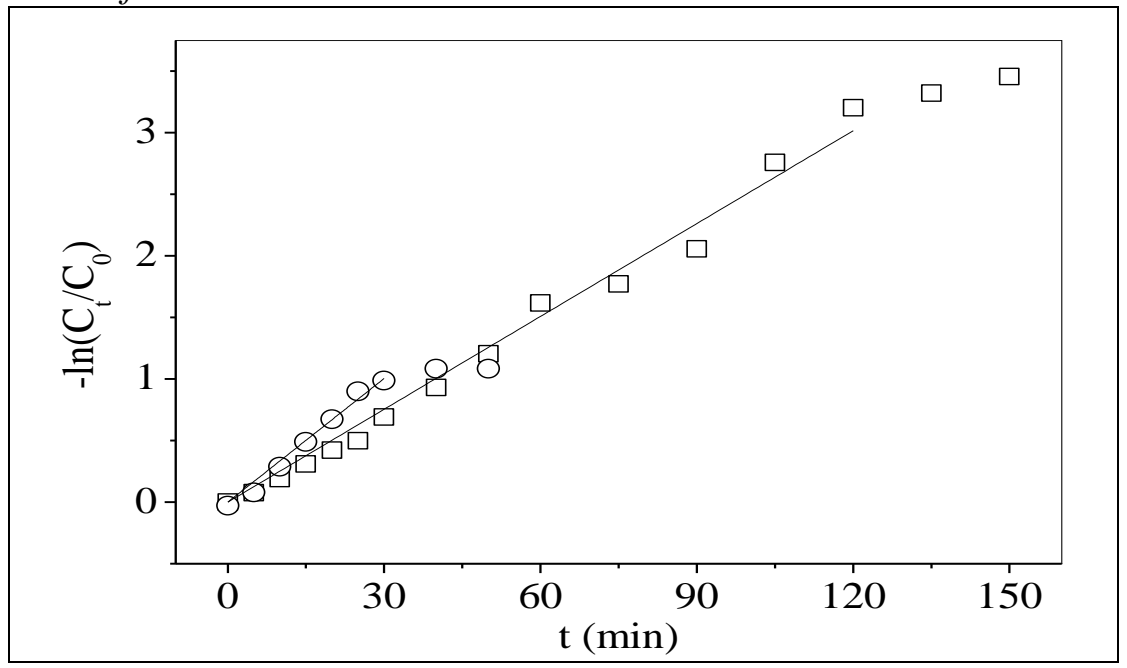


Figure 9 shows plots of $-\ln \left(C_{t} / C_{0}\right)$ of methylene blue versus irradiation time for the photocatalytic degradation of methylene blue on titanate nanotubes. If one disregards the last two points, where there was no more notable change of methylene blue concentration, data obey a linear pattern proving that pseudo-firstorder kinetic is an acceptable model for photocatalytic dye degradation. The apparent first order rate constants are given by the slope and yield 0.0251 and $0.0335 \mathrm{~min}^{-1}$ for as-prepared and calcined nanotubes, respectively. Due to differences in photocatalysis process setup and parameters, absolute values of rate constants cannot be directly compared with literature data. However, it can be observed that calcination slightly increased the photocatalytic activity of titanate nanotubes. Nam et al. (2013) also reported slightly faster degradation of methylene blue in the presence of calcined titania nanotubes and attribute this increase of degradation rate to the appearance of low amount of anatase phase. We believe that increased photocatalytic activity of calcined nanotubes is a consequence of both, the presence of anatase, i.e. titanate nanotube/anatase heterostructure, as well as reduced band gap value. As noted by Sun et al. (2015) (although for the $\mathrm{TiO}_{2}(\mathrm{~B}) /$ anatase heterostructure) while reduced band gap enables more intense photogeneration of electrons and holes, the presence of heterostructure enhanced their separation. At the same time, the specific surface area of calcined sample was reduced in comparison with the as-prepared one, but not so drastically to overwhelm previous two factors. The photodegradation process depends on the number of generated electrons in conduction and holes in valence band. The number of generated electrons and holes depends on the band gap, the smaller the band gap is, the greater number of photons possess the energy higher than the band gap and the greater is the number of electrons and holes formed when titanate nanotubes are irradiated. If the energized electrons don't recombine with the holes, the electron-hole pairs can participate in redox reactions on the surface of the photocatalyst. It appears that heterostructure prevents the recombination of electrons-hole pair (Salehi et al., 2012).

\section{Conclusions}

Titanate nanotubes were prepared through an alkaline hydrothermal treatment of titania followed by proton ion exchange and calcination at a $250^{\circ} \mathrm{C}$ for $2 \mathrm{~h}$. Calcination brings about loss of interlayer water and partial transformation of nanotubes to anatase phase. The structural change is accompanied with the reduction of specific surface area from 334.87 to $301.80 \mathrm{~m}^{2} \mathrm{~g}^{-1}$ and reduction of band gap from 3.45 to $3.2 \mathrm{eV}$.

Pseudo-second-order model was the most appropriate to describe the adsorption of methylene blue on titanate nanotubes pointing out to the prevalence of chemical sorption. Titanate nanotubes samples showed different affinity toward methylene blue, $48.45 \mathrm{mg} \mathrm{g}^{-1}$ and $95.24 \mathrm{mg} \mathrm{g}^{-1}$ for the as-prepared and calcined nanotubes, respectively due to a greater number of active sites for dye molecule adsorption at the surface of the calcined sample. The equilibrium adsorption was attained in 120min. Further analysis indicated that the adsorption 
process is controlled by intraparticle diffusion and surface sorption and that contribution of surface sorption in adsorption rate control is greater for the calcined sample.

The pseudo-first-order kinetic is an acceptable model for photocatalytic dye degradation process on titanate nanotubes. Calcination slightly increased the photocatalytic activity of titanate nanotubes, which is a consequence of the presence of titanate nanotube/anatase heterostructure and reduced band gap value. Calcination at $250^{\circ} \mathrm{C}$ for $2 \mathrm{~h}$ improved the adsorption and photocatalytic properties of titanate nanotubes.

\section{Acknowledgements}

The support of University of Zagreb is gratefully acknowledged.

\section{References}

Abida, B., Chirchi, L., Baranton, S., Napporn, T. W., Morais, C., Léger, J.-M., Ghorbel, A. 2013. Hydrogenotitanates nanotubes supported platinum anode for direct methanol fuel cell. J. Power Sources 241 (Nov. 2013), 429-439.

An'amt, M. N., Huang, N. M., Radiman, S., Lim, H. N., Muhamad, M. R. 2014. Triethanolamine-solution for rapid hydrothermal synthesis of titanate nanotubes, Sains Malays. 43, 1 (Jan. 2014),137-144.

Bavykin, D. V., Walsh, F. C. 2009. Elongated titanate nanostructures and their applications. Eur. J. Inorg. Chem. 8 (Mar. 2009), 977-997.

Bavykin, D. V., Redmond, K. E., Nias, B. P., Kulak, A. N., Walsh, F. C. 2010. The effect of ionic charge on the adsorption of organic dyes onto titanate nanotubes. Aust. J. Chem. 63, 2 (Feb. 2010), 270-275.

Buchholcz, B., Haspel, H., Oszko, A. Kukovecz, A., Konya, Z. 2017. Titania nanotube stabilized $\mathrm{BiOCl}$ nanoparticles in visible-light photocatalysis. RSC Adv. 7 (Mar. 2017) 16410-16422.

Chekir, N., Benhabiles, O., Tassalit, D., Aicha Laoufi, N., Bentahar, F. 2016. Photocatalytic degradation of methylene blue in aqueous suspensions using $\mathrm{TiO}_{2}$ and ZnO. Desalination and Water Treatment 57, 13 (2016) 6141-6147.

El-Wakil, A. M., Abou El-Maaty, W. M., Awad, F. S., Oudah, A. A. 2015. Solid phase extraction and determination of cationic azo dye from aqueous solution using dried papyrus plant, IJSR 4, 2 (Feb. 2015) 2045-2051.

Gandhimathi, R., Ramesh, S. T., Sindhu, V., Nidheesh, P. V. 2013. Bottom ash adsorption of basic dyes from their binary aqueous solutions. Songklanakarin J. Sci. Technol. 35, 3 (May-Jun. 2013) 339-347.

Hosseinpour, P. M., Yung, D., Panaitescu, E., Heiman, D., Menon, L., Budil, D., Lewis, L. H. 2014. Correlation of lattice defects and thermal processing in the crystallization of titania nanotube arrays. Mat. Res. Express 1, 045018 (Oct. 2014) 1-14.

Hu, K., Xiao, X., Cao, X., Hao, R., Zuo, X., Zhang, X., Nan, J. 2011. Adsorptive separation and photocatalytic degradation of methylene blue dye on titanate nanotube powders prepared by hydrothermal process using metal Ti particles as a precursor. $J$. Hazard. Mater. 192, 2 (Aug. 2011) 514-520.

Iijima, S. 1991. Helical microtubules of graphitic carbon, Nature 354 (Nov. 1991) 56-58. 
Jose, M., Harsha, N., Suhailath, K., Peer Mohamed, A., Shukla, S. 2016. Hydrogen phosphate anions modified hydrogen titanate nanotubes for methylene blue adsorption from aqueous solution: Validating novel method of predicting adsorption capacity, J. Environ. Chem. Eng. 4, 1 (Mar. 2016) 1295-1307

Kasuga, T., Hiramatsu, M., Hoson, A., Sekino, T., Niihara, K. 1998. Formation of titanium oxide nanotube. Langmuir 14, 12 (May 1998) 3160-3163.

Lee, C.-K., Liu, S.-S., Chen, H.-C. 2009. Application of hydrothermal method derived titanate nanotubes as adsorbents. Recent Pat. Nanotech. 3, 3 (Nov. 2009) 203-212.

Liu, R., Yang, W.-D., Chueng, H.-J., Ren, B.-Q. 2015. Preparation and application of titanate nanotubes on dye degradation from aqueous media by UV irradiation. $J$ Spectrosc. 680183 (2015) $1-9$.

Luttrell, T., Halpegamage, S., Tao, J., Kramer, A., Sutter, E., Batzill, M. 2014. Why is anatase a better photocatalyst than rutile? - Model studies on epitaxial $\mathrm{TiO}_{2}$ films. Sci. Rep. 4, 4043 (Feb. 2014) 1-7.

Maxim, F., Ferreira, P., Vilarinho, P. M. 2011. Influence of the neutralization process on the preparation of titanate nanotubes by hydrothermal synthesis. J. Porous Mat. 18, 1 (Feb. 2011) $37-45$.

Morgado Jr., E., de Abreu, M. A. S., Pravia, O. R. C., Marinkovic, B. A., Jardim, P. M., Rizzo, F. C., Araújo, A. S. 2006. A study on the structure and thermal stability of titanate nanotubes as a function of sodium content. Solid State Sci. 8, 8 (Aug. 2006) 888-900.

Morgado Jr, E., Jardim, P. M., Marinkovic, B. A., Rizzo, F. C., de Abreu, M. A. S., Zotin, J. L., Araujo, A. S. 2007. Multistep structural transition of hydrogen trititanate nanotubes into $\mathrm{TiO}_{2}-\mathrm{B}$ nanotubes: A comparison study between nanostructured and bulk materials. Nanotechnology 18, 495710 (Dec. 2007) 1-10.

Nam, C. T., Yang, W.-D., Duc, L. M. 2013. Study on photocatalysis of $\mathrm{TiO}_{2}$ nanotubes prepared by methanol - thermal synthesis at low temperature. Bull. Mater. Sci. 36, 5 (Oct. 2013) 779-788.

Salehi, M., Hashemipour, H., Mirzaee, M., 2012. Experimental study of influencing factors and kinetics in catalytic removal of methylene blue with $\mathrm{TiO}_{2}$ nanopowder. $J$. Environ. Eng. - ASCE 2, 1 (2012) 1-7.

Sandoval, A., Hernández-Ventura, C., Klimova, T. E., 2017. Titanate nanotubes for removal of methylene blue dye by combined adsorption and photocatalysis. Fuel 198 (Jun. 2017) 22-30.

Subramaniam, M. N., Goh, P. S., Abdullah, N., Lau, W. J., Ng, B. C., Ismail, A. F., 2017. Adsorption and photocatalytic degradation of methylene blue using high surface area titanate nanotubes (TNT) synthesized via hydrothermal method. J Nanopart. Res. 19, 220 (Jun. 2017) 1-13.

Sun, P., Wei, Y., Wang, C., Zhang, X. 2015. Vacuum heat treated titanate nanotubes for visible-light photocatalysis. New J. Chem. 39, 2 (Feb. 2015) 1281-1286.

Suzuki, Y., Yoshikawa, S. 2004. Synthesis and thermal analyses of $\mathrm{TiO}_{2}$-derived nanotubes prepared by the hydrothermal method. J. Mater. Res. 19, 4 (Apr. 2004) 982-985.

Umek, P., Cerc Korošec, R., Jančar, B., Dominko, R., Arčon, D. 2007. The influence of reaction temperature on the morphology of sodium titanate 1D nanostructures and their thermal stability. J. Nanosci. Nanotechnol. 7, 10 (Oct. 2007) 3502-3508.

Valencia, S., Marín, J., M., Restrepo, G. 2010. Study of the bandgap of synthesized titanium dioxide nanoparticules using the sol-gel method and a hydrothermal treatment, TOMSJ 4 (2010) 9-14. 
Vol. 5, No. $1 \quad$ Kurajica et al.: Adsorption and Degradation Kinetics of Methylene...

Xiong, L., Yang, Y., Mai, J., Sun, W., Zhang, C., Wei, D., Chen, Q., Nia, J. 2010. Adsorption behavior of methylene blue onto titanate nanotubes, Chem. Eng. J. 156, 2 (Jan. 2010) 313-320.

Zhang, M., Jin, Z., Zhang, J., Guo, X., Yang, J., Li, W., Wang, X., Zhang, Z. 2004. Effect of annealing temperature on morphology, structure and photocatalytic behavior of nanotubed $\mathrm{H}_{2} \mathrm{Ti}_{2} \mathrm{O}_{4}(\mathrm{OH})_{2}$, J. Mol. Catal. A: Chem. 217, 1-2 (Aug. 2004) 203-210.

Zhang, L., Lin, H., Wang, N., Lin, C., Li, J., 2007. The evolution of morphology and crystal form of titanate nanotubes under calcination and its mechanism, J. Alloy. Compd. 431, 1-2 (Apr. 2007) 230-235. 